\title{
Comparison of Cervical Alignment and Clinical Outcomes in Patients with Os Odontoideum versus $\mathrm{N}$ on-Os Odontoideum after Atlantoaxial Fixation
}

\author{
Farid Yudoyono ${ }^{1,2, *}$, \\ Jiin Kang ${ }^{1, \star}$, Yoon $\mathrm{Ha}^{1}$ \\ ${ }^{1}$ Department of Neurosurgery, \\ Spine and Spinal Cord Institute, \\ Yonsei University College of \\ Medicine, Seoul, Korea, \\ ${ }^{2}$ Department of Neurosurgery, \\ Hasan Sadikin Hospital, Faculty of \\ Medicine, Universitas Padjadjaran, \\ Bandung, Indonesia
}

\section{Corresponding Author:}

Yoon $\mathrm{Ha}$

Department of Neurosurgery, Spine and Spinal Cord Institute, Yonsei University College of Medicine, Seoul 03722, Korea

Tel: +82-2-2228-2151

Fax: +82-2-393-9979

E-mail: hayoon@yuhs.ac

*These authors contributed equally to this study and should be considered co-first authors.

Received: December 10, 2017 Revised: December 21, 2017 Accepted: December 26, 2017

Copyright (C) 2017 by The Korean Spinal Neurosurgery Society

This is an open access article distributed under the terms of the Creative Commons Attribution Non-Commercial License (http://creativecommons.org/licenses/bync/4.0/) which permits unrestricted noncommercial use, distribution, and reproduction in any medium, provided the original work is properly cited.

Objective: The purpose of this study was to compare the effect of atlantoaxial fixation on cervical alignment and clinical outcomes in patients with os odontoideum (OO) versus non-os odontoideum (non-OO).

Methods: A total of 119 patients who underwent atlantoaxial fixation for instability were identified between January 1998 and January 2014. Inclusion criteria included age more than 21 years and diagnosis of $\mathrm{OO}$ and non-OO. There were $22 \mathrm{OO}$ patients, and 20 non-OO patients. Measuring the $\mathrm{Oc}-\mathrm{C} 1 \mathrm{Cobb}$ angle, $\mathrm{C} 1-2 \mathrm{Cobb}$ angle, $\mathrm{C} 2-7 \mathrm{Cobb}$ angle, and $\mathrm{C} 2-7$ sagittal vertical axis (SVA) was assessed. Clinical outcome was assessment of suboccipital pain was determined using a visual analogue scale (VAS), and Japanese Orthopedic Association (JOA) scores were obtained in all patients pre- and postoperatively.

Results: The preoperative $\mathrm{C} 1-2$ angle in the $\mathrm{OO}$ group $\left(26.02^{\circ} \pm 10.53^{\circ}\right)$ was significantly higher than the non-OO group ( $\mathrm{p}=0.04)$. After $\mathrm{C} 1-2$ fixation, the $\mathrm{OO}$ group had significantly higher kyphotic change in the $\mathrm{C} 1-2$ angle $(\Delta \mathrm{C} 1-2)\left(3.2^{\circ} \pm 7.3^{\circ}[\mathrm{OO}]\right.$ vs. $-1.46^{\circ} \pm 7.21^{\circ}$ [non-OO] $(p=0.04)$, and higher decrease in postoperative C2-7 SVA ( $\triangle \mathrm{C} 2-7 \mathrm{SVA})(5.64 \pm 11.56 \mathrm{~mm}[\mathrm{OO}] \mathrm{Vs}$. $-0.51 \pm$ $6.57 \mathrm{~mm}$ [non-OO]) $(p=0.04)$. Both groups showed improvements in the health related quality of life (HRQOL) after surgery based on the VAS and JOA score $(p<0.001)$.

Conclusion: After fixation, kyphotic angular change in atlantoaxial joint and decrease $\mathrm{C} 2-7$ SVA were marked in the $\mathrm{OO}$ group. Both the $\mathrm{OO}$ and non-OO groups improved in neurological function and outcome after surgery.

Key Words: Os odontoideum, Atlantoaxial instability, C2 vertebra, Vertebra axis, Cervical, Atlantoaxial fusion

\section{INTRODUCTION}

Atlantoaxial articulation is unique part with full range of motion in the spine which depends on ligamentous support and the integrity of the odontoid for its stability. The etiology of atlantoaxial instability includes trauma, congenital malformations, os odontoideum (OO), rheumatoid arthritis, malignancies and skeletal dysplasias. $\mathrm{OO}$ is an anomaly defined as an ossicle with smooth circumscribed margins and no osseous continuity with the body of $\mathrm{C2}^{8,10,20)}$. It was firstly described in 1886 by Giacomini and is a cause of atlantoaxial instability in pediatric patients. Current evidence points to traumatic etiologies in the majority of patients ${ }^{2,17}$. $\mathrm{OO}$ is difficult to treat when associated with cervicomedullary compression, long-term displacement, and myelopathy. There is currently no consensus regarding the optimal management of $\mathrm{OO}$. For asymptomatic OO, some have advocated regular clinical and radiological exa- minations and if there is evidence of C1-2 instability, to proceed with surgical stabilization ${ }^{1,4)}$. However, few reports have elucidated the cervical sagittal alignment of $\mathrm{OO}$ patients versus non-OO patients after an atlantoaxial fixation procedure. Moreover, the biomechanical effect of C1-2 fixation on adjacent segments remains unknown $^{13,26)}$. In this investigation, we studied the effect of atlantoaxial fixation on cervical sagittal alignment, as well as range of motion between $\mathrm{OO}$ and non-OO patients.

\section{MATERIALS AND METHODS}

\section{Patient Demographics}

Between 1998 and 2014, 245 patients with atlantoaxial instability were registered in the Yonsei University Medical Center database. A total of 119 patients who underwent AA fixation by transarticular (TAS) and screw-rod construct (SRC) technique were identified. Patients with any injuries that precluded them from being 
able to obtain flexion and extension radiographs were also excluded. There were $22 \mathrm{OO}$ patients, and 20 non-OO patients, which included 6 patients with rheumatoid arthritis, 11 degenerative patients, and 3 patients with trauma. Regular follow-up was performed at 3, 12, 24, 36, 48, 56, and 72 months following surgery. Occipitocervical fusion and other types of posterior atlantoaxial fixation procedures, including the use of atlantal translaminar screws, atlantoaxial interlaminar hooks/rods, and intraarticular screws with interlaminar clamps were excluded from the study. All radiographic and health related quality of life (HRQOL) data were reviewed. This study was approved by Yonsei University Institutional Review Board (IRB Number: 4-2017-0209).

\section{Surgical Selection and Methods}

The patients were placed in a prone position with the skull fixed by a Mayfield clamp. The neck was positioned to optimize access by flexing slightly at the occiput while extending the subaxial spine. An attempt was made to reduce the C1-2 articulation during this positioning process. Procedures were assisted by fluoroscopy. A midline incision was made over $\mathrm{C} 1-2$ but extended distally to allow the required drill angulation and the posterior aspects of C-1 and C-2 were fully exposed. Subperiosteal exposure of the $\mathrm{C} 1$ arch and $\mathrm{C} 2$ posterior elements was performed. A right-angled hook was used to palpate the medial walls of the C1 lateral mass and the $\mathrm{C} 2$ pars, to help guide for the screw. We placed the screw after reducing the subluxation and check final implant positioning by fluoroscopy. In TAS technique, iliac bone block was fixed via interlaminar wiring. In SRC, autologous bone graft was implanted

\section{Radiographic Evaluations}

Pre- and postoperative radiographs were obtained in all patients in upright flexion, neutral, and extension positions. Postoperative radiographs were obtained approximately 2 years after surgery. Preoperative AA instability was documented in all patients by plain radiographs, dynamic flexion-extension radiographs, and computed tomography studies. Magnetic resonance imaging supplemented the evaluation in many cases to help define ligamentous disorders. The $\mathrm{Oc}^{-} \mathrm{C} 1$ angle was measured from the McGregor line drawn from the posterosuperior aspect of the hard palate to the most caudal point on the midline occipital curve and a line drawn parallel to the inferior aspect of C-1. The C1-2 angle was defined as the angle subtended by a line drawn parallel to the inferior aspect of C-1 and a line drawn parallel to the inferior endplate of $\mathrm{C}-2$. Cervical lordosis (CL) was assessed by the $\mathrm{C} 2-7$ Cobb angle was defined as the angle subtended by a line drawn parallel to the inferior endplate of the C-2 vertebral body and a line drawn parallel to the inferior endplate of the C-7 vertebral body (Fig. 1). Implant failure was considered if there was an implant pullout, loosening or separation by plain X-ray, and fusion was suggested by the absence of motion on flexion and extension film and the presence of bridging bone on CT or plain X-ray. The Oc- ${ }^{-} 1, \mathrm{C}^{-}-2$ and $\mathrm{C} 2-7$ angles were measured before and after surgery. The C2-7 SVA was defined as the distance from the posterosuperior corner of $\mathrm{C} 7$ and the vertical line from the center of the $\mathrm{C} 2$ body. Changes in the cervical alignment $(\Delta)$ were calculated with the following formula: alignment change $\left({ }^{\circ}\right)=($ preoperative $\mathrm{C} 2-7$ Cobb angle)-(postoperative C2-7 Cobb angle), According to this formula, alignment changes $>0^{\circ}$ were considered postoperative loss of $\mathrm{CL}$ or kyphotic changes ${ }^{13,26}$. The difference between the pre- and postoperative C1-2 and C2-7 angles and the angle of atlantoaxial fixation was established. The extent of change in $\mathrm{C} 2-7$ was evaluated. In addition, the effect on adjacent segments was evaluated based on the extent of changes in $\mathrm{Oc}^{-} \mathrm{C} 1$ before and after surgery. These evaluations were performed between the $\mathrm{OO}$ and non-OO groups before and after surgery

\section{Statistical analysis}

The statistical analysis was performed using SAS 9.1 (SAS Institute Inc., Cary, NC, USA). A p-value $<0.05$ was considered statistically significant.

\section{RESULTS}

\section{Patient Demographics}

The average patient age of the OO group was $43.68 \pm 15.50$

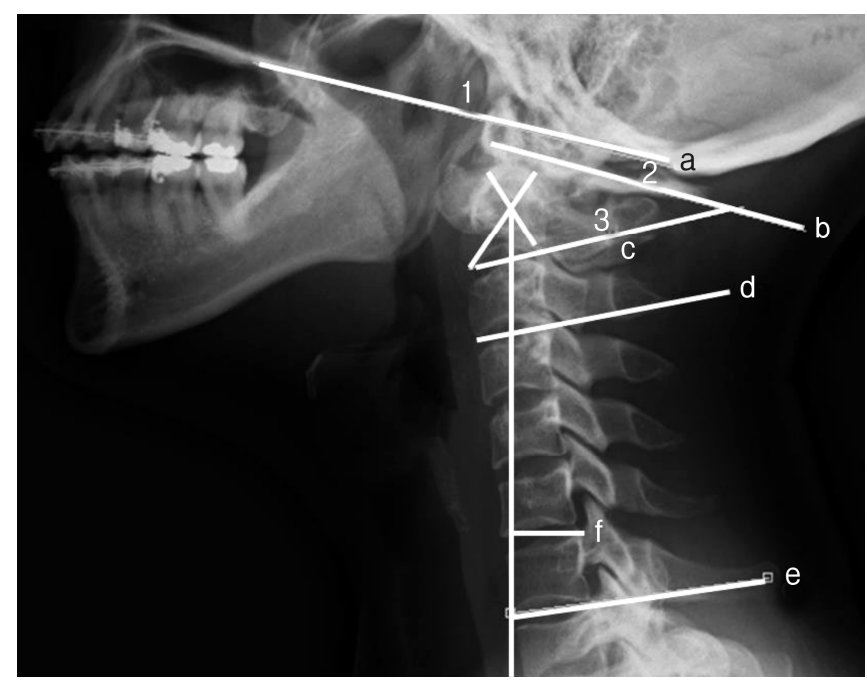

Fig. 1. Sagittal cervical alignment parameters. (a-b) $\mathrm{Oc}-\mathrm{C} 1$ angle, (b-c) C1-2 angle, (d-e) C2-7 angles, and (f) C2-7 sagittal vertical axis (SVA) were measured between the lines shown in the figure. The $\mathrm{Oc}^{-} \mathrm{C} 1$ angle was calculated by subtracting the angle between the $\mathrm{McGregor}$ line and the line passing through the inferior aspect of the atlas in extension from that in the forward flexion. The C2-7 SVA was defined as the distance from the posterosuperior corner of $\mathrm{C} 7$ and the vertical line from the center of the $\mathrm{C} 2$ body. The $\mathrm{C} 2-7$ angle was calculated by subtracting the angle between the line drawn horizontal to the inferior endplate of the $\mathrm{C}-2$ vertebral body and the line drawn horizontal to the inferior endplate of the $\mathrm{C}-7$ vertebral body in extension from that in the forward flexion. 
years and the non-OO group was $52.95 \pm 14.82$ years $(\mathrm{p}=0.06)$. There were 3 male and 19 female patients in the $\mathrm{OO}$ group and 9 male and 11 female patients in the non-OO group $(\mathrm{p}<0.01)$. An average follow-up in the OO group was $24.23 \pm 19.17$ months and the non-OO group was $24.7 \pm 11.8$ months $(\mathrm{p}=0.92)$ (Table 1$)$.

\section{Measurements}

The results of measurement taken in the $\mathrm{OO}$ and the non-OO groups including means, standard deviations, and significance values are presented in Tables 2, 3 .

\section{C1-2 and C2-7 Cobb Angle Measurements}

In the $\mathrm{OO}$ group, there was a statistically significant decrease

Table 1. Patients characteristics of $\mathrm{OO}$ and non-OO groups

\begin{tabular}{lccc}
\hline \hline Characteristic & $\begin{array}{c}\text { OO group } \\
(\mathrm{n}=22)\end{array}$ & $\begin{array}{c}\text { Non-OO group } \\
(\mathrm{n}=20)\end{array}$ & p-value \\
\hline Age (yr) & $43.68 \pm 15.50$ & $52.95 \pm 14.82$ & 0.06 \\
Follow-up time (mo) & $24.23 \pm 19.17$ & $24.7 \pm 11.8$ & 0.92 \\
Sex, male:female & $3: 19$ & $9: 11$ & $<0.01^{*}$ \\
Implant failure & $1(4.5)$ & $2(10)$ & 0.47 \\
Fusion & $22(100)$ & $20(100)$ & 0.96 \\
\hline
\end{tabular}

Values are presented as mean \pm standard deviation or number (\%). OO, os odontoideum.

"p $\leq 0.05$, t-test, chi-square, Fisher exact test.

Table 2. Comparison of sagittal parameters before and after surgery for each OO group and non-OO groups

\begin{tabular}{|c|c|c|c|}
\hline Parameter & Preoperative & Postoperative & p-value \\
\hline \multicolumn{4}{|l|}{ OO group } \\
\hline $\mathrm{O}-\mathrm{C} 1\left(^{\circ}\right)$ & $11.3 \pm 7.36$ & $10.74 \pm 6.44$ & 0.51 \\
\hline $\mathrm{C} 1-2\left(^{\circ}\right)$ & $26.02 \pm 10.53$ & $22.82 \pm 8.30$ & $0.03 *$ \\
\hline $\mathrm{C} 2-7\left(^{\circ}\right)$ & $17.63 \pm 13.61$ & $15.63 \pm 4.20$ & 0.26 \\
\hline C2-7 SVA (mm) & $19.36 \pm 10.31$ & $13.7 \pm 9.48$ & $0.02 *$ \\
\hline $\mathrm{O}-\mathrm{C} 1 \mathrm{ROM}\left({ }^{\circ}\right)$ & $21.48 \pm 10.41$ & $21.44 \pm 8.70$ & 0.97 \\
\hline $\mathrm{C} 1-2 \operatorname{ROM}\left(^{\circ}\right)$ & $42.62 \pm 11.44$ & $45.56 \pm 14.36$ & 0.15 \\
\hline $\mathrm{C} 2-7$ ROM $\left(^{\circ}\right)$ & $64.02 \pm 24.17$ & $61.96 \pm 19.45$ & 0.43 \\
\hline \multicolumn{4}{|l|}{ Non-OO group } \\
\hline $\mathrm{O}-\mathrm{C} 1\left(^{\circ}\right)$ & $11.38 \pm 6.89$ & $8.43 \pm 5.32$ & $0.01 *$ \\
\hline $\mathrm{C} 1-2\left(^{\circ}\right)$ & $19.76 \pm 8.48$ & $21.23 \pm 7.85$ & 0.35 \\
\hline $\mathrm{C} 2-7\left(^{\circ}\right)$ & $16.76 \pm 9.44$ & $12.76 \pm 9.14$ & $0.01 *$ \\
\hline C2-7 SVA $(\mathrm{mm})$ & $7.5 \pm 11.65$ & $7.51 \pm 11.65$ & 0.45 \\
\hline $\mathrm{O}-\mathrm{C} 1 \mathrm{ROM}\left({ }^{\circ}\right)$ & $19.97 \pm 11.80$ & $18.8 \pm 8.92$ & 0.50 \\
\hline $\mathrm{C} 1-2 \operatorname{ROM}\left(^{\circ}\right)$ & $44.19 \pm 14.54$ & $43.28 \pm 17.42$ & 0.77 \\
\hline $\mathrm{C} 2-7 \mathrm{ROM}\left({ }^{\circ}\right)$ & $53.89 \pm 19.91$ & $57.7 \pm 16.22$ & 0.05 \\
\hline
\end{tabular}

Values are presented as mean \pm standard deviation or number (\%). OO, os odontoideum; SVA, sagittal vertical axis; ROM, range of motion.

$* \mathrm{p} \leq 0.05$, paired t-test. in the C1-2 Cobb angles (preoperative vs. postoperative) as well as changes of $\mathrm{C} 1-2$ angles ( $\Delta \mathrm{C} 1-2)$ after surgery. The mean $\mathrm{C} 1-2 \mathrm{Cobb}$ angles in preoperative value was $26.02^{\circ} \pm 10.53^{\circ}$ and significantly decreased to postoperative value of $22.82^{\circ} \pm 8.3^{\circ}(\mathrm{p}=$ 0.03 ) (Table 2). However, In the non-OO group, the mean preoperative $\mathrm{C} 1-2 \mathrm{Cobb}$ angles was $19.76^{\circ} \pm 8.48^{\circ}$ and postoperative $\mathrm{C} 1-2 \mathrm{Cobb}$ angles was $21.23^{\circ} \pm 7.85^{\circ}(\mathrm{p}=0.35)$ (Table 2). After $\mathrm{C} 1-2$ fixation, the $\mathrm{OO}$ group had significantly higher kyphotic change in the $\mathrm{C} 1-2$ angle $(\Delta \mathrm{C} 1-2)\left(3.2^{\circ} \pm 7.3^{\circ}[\mathrm{OO}]\right.$ vs. $-1.46^{\circ} \pm$ $7.21^{\circ}$ [non-OO]) $(\mathrm{p}=0.04)$ (Table 3$)$.

In the non-OO group, there was a statistically significant decrease in the $\mathrm{C} 2-7 \mathrm{Cobb}$ angles (preoperative vs. postoperative). In the $\mathrm{OO}$ group, the mean $\mathrm{C} 2-7 \mathrm{Cobb}$ angles in preoperative value was $17.63^{\circ} \pm 13.61^{\circ}$ and postoperative value was $15.63^{\circ} \pm$ $4.2^{\circ}(\mathrm{p}=0.26)$. However, in the non-OO group, the mean $\mathrm{C} 2-7$ Cobb angles in preoperative value was $16.76^{\circ} \pm 9.44^{\circ}$ and significantly decreased to postoperative value of $12.76^{\circ} \pm 9.14^{\circ}(\mathrm{p}=$ 0.01 ). There was also a statistically higher postoperative $\mathrm{C} 2-7$ $\mathrm{ROM}$ in the $\mathrm{OO}$ group than non-OO group $(\mathrm{p}=0.02)$ (Table 3 ).

\section{C2-7 SVA}

In the $\mathrm{OO}$ group, there was a statistically significant higher preoperative C2-7 SVA value and change in C2-7 SVA after surgery $(\triangle \mathrm{C} 2-7 \mathrm{SVA})$ than the non-OO group. In the $\mathrm{OO}$ group, the mean C2-7 SVA in preoperative value was $19.36 \pm 10.31 \mathrm{~mm}$ and significantly decreased to postoperative value of $13.7 \pm 9.48$ $\mathrm{mm}(\mathrm{p}=0.02)$. In the non-OO group, the mean $\mathrm{C} 2-7$ SVA preoperative value was $7.5 \pm 11.65 \mathrm{~mm}$ and postoperative value was $7.51 \pm 11.65 \mathrm{~mm}(\mathrm{p}=0.45)$. The change in $\mathrm{C} 2-7$ SVA after surgery $(\triangle \mathrm{C} 2-7 \mathrm{SVA})$ was significantly higher in $\mathrm{OO}$ group $(5.64 \pm 11.56$ $\mathrm{mm})$ than the non-OO group $(-0.51 \pm 6.56 \mathrm{~mm})(\mathrm{p}=0.04)$ (Table 3$)$.

Table 3. Summary of preoperative (preop) and postoperative (postop) characteristics of $\mathrm{OO}$ and non-OO groups

\begin{tabular}{lccl}
\hline \hline & OO group & Non-OO group & p-value \\
\hline O-C1 preop $\left(^{\circ}\right)$ & $11.29 \pm 7.35$ & $11.38 \pm 6.89$ & 0.97 \\
C1-2 preop $\left(^{\circ}\right)$ & $26.02 \pm 10.53$ & $19.76 \pm 8.48$ & $0.04^{*}$ \\
C2-7 preop $\left(^{\circ}\right)$ & $17.63 \pm 13.61$ & $16.76 \pm 9.44$ & 0.81 \\
O-C1 postop $\left(^{\circ}\right)$ & $10.73 \pm 6.44$ & $8.43 \pm 5.32$ & 0.22 \\
$\Delta$ O-C1 $\left(^{\circ}\right)$ & $0.56 \pm 9.45$ & $2.95 \pm 4.83$ & 0.20 \\
C1-2 postop $\left(^{\circ}\right)$ & $22.82 \pm 8.29$ & $21.23 \pm 7.85$ & 0.53 \\
$\Delta \mathrm{C} 1-2\left(^{\circ}\right)$ & $3.2 \pm 7.33$ & $-1.47 \pm 7.21$ & $0.04^{*}$ \\
$\mathrm{C} 2-7$ postop $\left(^{\circ}\right)$ & $15.58 \pm 11.88$ & $12.76 \pm 9.14$ & 0.40 \\
$\Delta \mathrm{C} 2-7\left(^{\circ}\right)$ & $2.05 \pm 9.84$ & $4.00 \pm 7.29$ & 0.47 \\
$\mathrm{C} 2-7$ ROM postop $\left(^{\circ}\right)$ & $61.97 \pm 19.46$ & $47.86 \pm 16.22$ & $0.02^{*}$ \\
$\mathrm{C} 2-7$ SVA preop $(\mathrm{mm})$ & $19.36 \pm 10.31$ & $7.50 \pm 11.65$ & $0.00^{*}$ \\
$\mathrm{C} 2-7$ SVA postop $(\mathrm{mm})$ & $13.72 \pm 9.47$ & $8.01 \pm 13.21$ & 0.11 \\
$\Delta \mathrm{C} 2-7$ SVA $(\mathrm{mm})$ & $5.64 \pm 11.56$ & $-0.51 \pm 6.56$ & $0.04^{*}$ \\
\hline
\end{tabular}

Values are presented as mean \pm standard deviation.

OO, os odontoideum; ROM, range of motion; SVA, sagittal vertical axis.

* $\mathrm{p} \leq 0.05$, independent $\mathrm{t}$-test. 
Farid Yudoyono et al.

Table 4. Health related quality of life preoperative and postoperative

\begin{tabular}{lccc}
\hline \hline Variable & Preoperative & Postoperative & p-value \\
\hline OO group & & & \\
VAS occipital & $4.87 \pm 2.13$ & $0.75 \pm 1.00$ & $0.01^{*}$ \\
JOA score & $15.31 \pm 1.2$ & $16.76 \pm 0.66$ & $0.00^{*}$ \\
Non-OO group & & & \\
VAS occipital & $4.65 \pm 2.26$ & $1.11 \pm 1.02$ & $0.02^{*}$ \\
JOA score & $15.68 \pm 1.53$ & $16.8 \pm 0.89$ & $0.01^{*}$ \\
\hline
\end{tabular}

Values are presented as mean \pm standard deviation.

VAS, visual analogue scale; JOA, Japanese Orthopedic Association; OO, os odontoideum.

* $\mathrm{p} \leq 0.05$, paired t-test.

\section{Oc-C1 measurements}

In the $\mathrm{OO}$ group, the mean $\mathrm{O}-\mathrm{C} 1 \mathrm{Cobb}$ angles in preoperative value was $11.3^{\circ} \pm 7.36^{\circ}$ and postoperative value was $10.74^{\circ} \pm 6.44^{\circ}$ $(\mathrm{p}=0.51)$. In the non-OO group, the mean $\mathrm{O}-\mathrm{C} 1 \mathrm{Cobb}$ angles in preoperative value was $11.38^{\circ} \pm 6.89^{\circ}$ and postoperative value was $8.43^{\circ} \pm 5.32^{\circ}(\mathrm{p}=0.01)$.

\section{HRQOL Measurements}

Results of HRQOL after surgery were summarized in Table 4. There were statistically significant improvements in the VAS after surgery in both groups $(\mathrm{p}<0.01)$. The mean VAS in the OO group was $4.87 \pm 2.13$ before and $0.75 \pm 1$ after surgery, and in the non-OO group, the mean VAS was $4.65 \pm 2.26$ before and $1.11 \pm 1.02$ after surgery. There were statistically significant improvements in the JOA scores in both groups $(\mathrm{p}<0.01)$. The mean JOA in the OO group was $15.31 \pm 1.2$ before and $16.76 \pm 0.66$ after surgery, and in the non-OO group, the mean JOA was $15.68 \pm 1.53$ before and $16.8 \pm 0.89$ after surgery.

\section{DISCUSSION}

$\mathrm{OO}$ with instability can be asymptomatic or present with a variety of symptoms, including occipital-cervical pain alone, myelopathy or intracranial symptoms or signs from vertebrobasilar ischemia ${ }^{21)}$. Recent studies have reported that the atlantoaxial angle plays an important role in high cervical alignment ${ }^{14,16}$. Furthermore, there is a lack of evidence with regard to the most suitable parameter for predicting postoperative loss of lordosis after atlantoaxial fixation. A previous study hypothesized that common radiographic changes included an increase in C1-2 lordosis and a decrease in C2-7 lordosis, which are produced by $\mathrm{C} 1-2$ fixation and posterior musculoligamentous injury during posterior surgery, $3,2,23$.

Previous studies reported that increase kyphosis in C1-2 after C1-2 fixation ${ }^{3,26}$. By contrast, in the present study, the mean $\mathrm{C} 1-2 \mathrm{Cobb}$ angle in the non-OO group was $19.76^{\circ} \pm 8.48^{\circ}$ before surgery and $21.23^{\circ} \pm 7.85^{\circ}$ after surgery $(\mathrm{p}=0.35)$, and the $\triangle \mathrm{C} 1-2$ was $-1.47^{\circ} \pm 7.21^{\circ}$. In the $\mathrm{OO}$ group, the $\mathrm{C} 1-2 \mathrm{Cobb}$ angle was $26.02^{\circ} \pm 10.5^{\circ}$ before surgery and $22.8^{\circ} \pm 8.3^{\circ}$ after sur- gery, and the $\Delta \mathrm{C} 1-2$ was $3.2^{\circ} \pm 7.3^{\circ}(\mathrm{p}=0.04)$ (Table 3). These findings explain that the $\mathrm{OO}$ patients have preoperative lordotic posture in $\mathrm{C} 1-2$ angle than non-OO patients. Also, final C1-2 angle after the surgery were almost identical in both groups $\left(21.23^{\circ}\right.$ in $\mathrm{OO}$ vs. $22.8^{\circ}$ in non-OO) imply that the mechanical characteristics of C1-2 instrumentation could induce identical angle at $\mathrm{C} 1-2$ in both groups $5,13,24,25$.

The present study also found in the OO group that $\mathrm{C} 2-7$ SVA decreased from $19.36 \pm 10.31 \mathrm{~mm}$ to $13.7 \pm 9.48 \mathrm{~mm}(\mathrm{p}=0.02)$ at the final follow up, along with high $\triangle \mathrm{C} 2-7 \mathrm{SVA}$ in the OO group $(\mathrm{p}=0.04)$. In order to maintain horizontal gaze, cervical spine alignment and radiological parameters will change reciprocally. Therefore, our finding can be explained by secondary to the realignment after atlantoaxial loss of lordosis and posterior musculoligamentous injury which could decrease $\Delta \mathrm{C} 2-7$ SVA.

In this study, both $\mathrm{OO}$ group and non-OO group decreased postoperative C2-7 Cobb angle. Our current findings in loss of $\mathrm{CL}$ at subaxial spine in both groups were similar to previous study ${ }^{11,12,15,16,23,27}$. Therefore, we support the hypothesis that the injury of musculoligamentous complex during the posterior cervical AA fixation may drive the cervical alignment to more kyphotic than preoperative value.

C2-7 ROM after surgery was higher in the OO group than the non-OO group. This current finding implies that the relatively younger patients population with less association with degenerative changes in the $\mathrm{OO}$ group may produce more $\mathrm{C} 2-7 \mathrm{ROM}$ after the surgery.

Although, it is still difficult to justify the relationship between AA fixation and CL, we could hypothesize from the summary of our results that the compensated higher cervical alignment in the OO group could have the potential to lead to greater SVA changes after surgery. After AA fixation, postoperative loss of lordosis was related to conditions, such as posterior muscle injury, age and degenerative change.

The present study reported that there are no differences in the fusion rate between the $\mathrm{OO}$ and non-OO groups, and the success rate of bony fusion was approximately $100 \%$ in both groups, which is similar to previous findings that reported ${ }^{6,22)}$. A screw break in the OO group (4.5\% [1 of 22]) in a previous study also resulted in implant failure ${ }^{18)}$.

In this study, perioperative HRQOL after treatment was also significantly different pre- and postoperatively (VAS suboccipital, $\mathrm{p}<0.01 ; \mathrm{JOA}, \mathrm{p}<0.01)$. This indicates that surgical procedures for atlantoaxial instability are satisfactory in decreasing suboccipital pain and neurological symptoms, which is similar to findings from a previous study ${ }^{19}$.

Our study has some notable limitations, including its retrospective design, small sample size, and that it was not blinded also cervical T1 slope was not performed. In addition, selection bias and several confounding factors could affect our results. However, despite these limitations, our study demonstrated the radiological characteristics of $\mathrm{OO}$ and non-OO patients. Our study is valuable to understanding the relationship between AA fixation and loss of lordosis after fixation in patients with $\mathrm{OO}$ and nonOO. Therefore, more consecutive data and future prospective 
clinical studies will be needed.

\section{CONCLUSION}

After fixation, kyphotic angular change in atlantoaxial joint and decrease C2-7 SVA were marked in the OO group. Both the $\mathrm{OO}$ and non-OO groups improved in neurological function and outcome after surgery.

\section{CONFLICT OF INTEREST}

No potential conflict of interest relevant to this article was reported.

\section{ACKNOWLEDGMENTS}

The authors would like to thank Dong-Su Jang, MFA (Medical Illustrator, Medical Research Support Section, Yonsei University College of Medicine, Seoul, Korea) for his help with the illustrations.

\section{REFERENCES}

1. Abd-El-Barr MM, Snyder BD, Emans JB, Proctor MR, Hedequist $\mathrm{D}$ : Combined preoperative traction with instrumented posterior occipitocervical fusion for severe ventral brainstem compression secondary to displaced os odontoideum: technical report of 2 cases. J Neurosurg Pediatr 25:724-729, 2016

2. Akpolat YT, Fegale B, Cheng WK: Treatment of os odontoideum in a patient with spastic quadriplegic cerebral palsy. J Clin Neurosci 22:1239-1243, 2015

3. Bahadur R, Goyal T, Dhatt SS, Tripathy SK: Transarticular screw fixation for atlantoaxial instability - modified Magerl's technique in 38 patients. J Orthop Surg Res 5:87, 2010

4. Chung JC, Jung SS, Park KS, Ha HG: Intraoperative vertebral artery angiography to guide c1-2 transarticular screw fixation in a patient with athetoid cerebral palsy. J Korean Neurosurg Soc 51:177-181, 2012

5. Fielding JW, Hensinger RN, Hawkins RJ: Os Odontoideum. J Bone Joint Surg Am 62:376-383, 1980

6. Goel A, Desai K, Muzumdar DP: Atlantoaxial fixation using plate and screw method: a report of 160 treated patients. Neurosurgery 51:1351-1356, 2002

7. Goel A, Laheri V: Plate and screw fixation for atlanto-axial subluxation. Acta Neurochir (Wien) 129:47-53, 1994

8. Grob D, Jeanneret B, Aebi M, Markwalder TM: Atlanto-axial fusion with transarticular screw fixation. J Bone Joint Surg Br 73: 972-976, 1991

9. Guo Q, Ni B, Yang J, Liu K, Sun Z, Zhou F, et al: Relation between alignments of upper and subaxial cervical spine: a radiological study. Arch Orthop Trauma Surg 131:857-862, 2011

10. Ikuchi K, Nakagawa H, Watanabe K, Kowada M: Bilateral vertebral artery occlusion secondary to atlantoaxial dislocation with os odontoideum: implication for prophylactic cervical stabilization by fusion--case report. Neurol Med Chir (Tokyo) 33:769-773, 1993

11. Johnson GM, Zhang M, Jones DG: The fine connective tissue archi- tecture of the human ligamentum nuchae. Spine (Phila Pa 1976) 25:5-9, 2000

12. Kim B, Yoon DH, Ha Y, Yi S, Shin DA, Lee CK, et al: Relationship between T1 slope and loss of lordosis after laminoplasty in patients with cervical ossification of the posterior longitudinal ligament. Spine J 16:219-225, 2016

13. Klimo P Jr, Kan P, Rao G, Apfelbaum R, Brockmeyer D: Os odontoideum: presentation, diagnosis, and treatment in a series of 78 patients. J Neurosurg Spine 9:332-342, 2008

14. Liu Q, Guo Q, Yang J, Zhang P, Xu T, Cheng X, et al: Subaxial cervical intradiscal pressure and segmental kinematics following atlantoaxial fixation in different angles. World Neurosurg 87:521528, 2016

15. Mukai Y, Hosono N, Sakaura H, Fujii R, Iwasaki M, Fuchiya T, et al: Sagittal alignment of the subaxial cervical spine after C1-C2 transarticular screw fixation in rheumatoid arthritis. J Spinal Disord Tech 20:436-441, 2007

16. Nolan JP Jr, Sherk HH: Biomechanical evaluation of the extensor musculature of the cervical spine. Spine (Phila Pa 1976) 13:9-11, 1988

17. Ohya J, Miyoshi K, Kitagawa T, Nakagawa S: Occipitalized os odontoideum: a case report. J Craniovertebr Junction Spine 5:170-172, 2014

18. Okamoto T, Neo M, Fujibayashi S, Ito H, Takemoto M, Nakamura $\mathrm{T}$ : Mechanical implant failure in posterior cervical spine fusion. Eur Spine J 21:328-334, 2012

19. Oshima S, Sudo H, Ito M, Abumi K: Subaxial sagittal alignment after atlantoaxial fixation techniques. J Spinal Disord Tech 28:E4955, 2015

20. Rahimizadeh A, Soufiani HF, Hassani V, Rahimizadeh A: Atlantoaxial subluxation due to an os odontoideum in an achondroplastic adult: report of a case and review of the literature. Case Rep Orthop 2015:142586, 2015

21. Rozzelle CJ, Aarabi B, Dhall SS, Gelb DE, Hurlbert RJ, Ryken TC, et al: Os odontoideum. Neurosurgery 72 Suppl 2:159-169, 2013

22. Suchomel P, Stulík J, Klézl Z, Chrobok J, Lukás R, Krbec M, et al: Transarticular fixation of C1-C2: a multicenter retrospective study. Acta Chir Orthop Traumatol Cech 71:6-12, 2004

23. Takeshita K, Peterson ET, Bylski-Austrow D, Crawford AH, Nakamura K: The nuchal ligament restrains cervical spine flexion. Spine (Phila Pa 1976) 29:E388-393, 2004

24. Toyama Y, Matsumoto M, Chiba K, Asazuma T, Suzuki N, Fujimura $\mathrm{Y}$, et al. Realignment of postoperative cervical kyphosis in children by vertebral remodeling. Spine (Phila Pa 1976) 19:25652570, 1994

25. Watanabe M, Toyama Y, Fujimura Y: Atlantoaxial instability in os odontoideum with myelopathy. Spine (Phila Pa 1976) 21:14351439, 1996

26. Yoshida G, Kamiya M, Yoshihara H, Kanemura T, Kato F, Yukawa $\mathrm{Y}$, et al: Subaxial sagittal alignment and adjacent-segment degeneration after atlantoaxial fixation performed using C-1 lateral mass and C-2 pedicle screws or transarticular screws. J Neurosurg Spine 13:443-450, 2010

27. Yoshimoto H, Ito M, Abumi K, Kotani Y, Shono Y, Takada T, et al: A retrospective radiographic analysis of subaxial sagittal alignment after posterior C1-C2 fusion. Spine (Phila Pa 1976) 29:175181,2004 